NEWS

\title{
Oldest gorilla ages our joint ancestor
}

The last common ancestor of humans and gorillas might have lived at least 2 million years earlier than previously thought. Fossilized teeth of the earliest gorilla ever discovered, dating to 10 million years ago, have been found in Africa, say researchers.

The new species (Chororapithecus abyssinicus) from Ethiopia, reported on page 921 of this issue, helps to fill in a huge gap in the fossil record. The team of Ethiopian and Japanese researchers has based its conclusion on just nine teeth from at least three individuals of the species, which were discovered in the desert scrubland of Afar about 170 kilometres east of Addis Ababa.

The teeth, eight molars and a

"Africa was the place of origin of both humans and modern African apes." canine, "are collectively indistinguishable from modern gorilla subspecies" in size, proportion and scan-revealed internal structure, says Gen Suwa of the University of Tokyo Museum, Japan, who led the study. The team argues that the gorilla's divergence date from the human lineage is not about 8 million years ago as previously surmised (S. Kumar et al. Proc. Natl Acad. Sci. USA 102, 18842-18847; 2005), but "greater than 10 to 11 million years ago" on the basis of the age of the new species. Functionally, he adds, the teeth already seem to be evolving - they could shear through a plant diet, a gorilla trait - although other herbivore apes also exist in the fossil record.

This finding could prompt discussions of how anthropologists and geneticists determine the hominin line's divergence from chimps, previously pegged at about 6 million years ago. "Chororapithecus abyssinicus suggests, once again, that Africa was the place of origin of both humans and modern African apes" - not Eurasia as some researchers have argued, says Suwa.

But palaeoanthropologist Jay Kelley, who studies primate teeth at the University of Illinois at Chicago and was not involved in the study, is sceptical. "I'm not convinced it is a gorilla," he says. More fossils, analysis and debate will be needed to determine whether

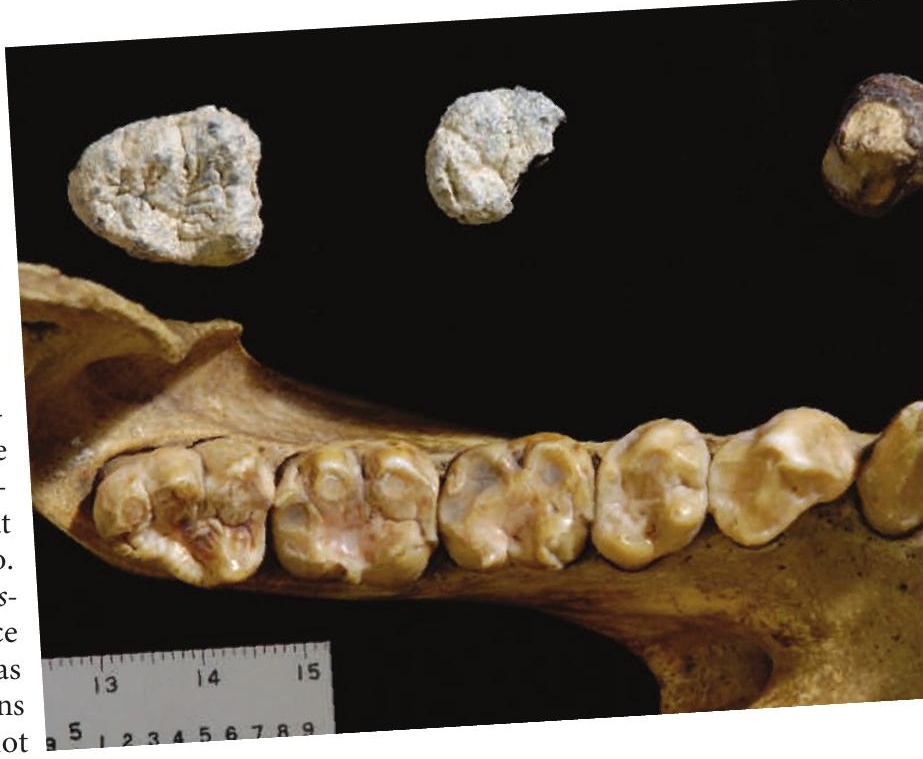

the specimen is ancestral to hominids, he adds. For now, he would be "very cautious" about using the specimen to realign divergence dates between hominins and gorillas-chimps.

Suwa's team is part of the Revealing Human Origins Initiative (RHOI), a project that searches at multiple sites in Africa, Europe

\section{Ocean circulation noisy, not stalling}

Suggestions of a substantial decline in the Atlantic Ocean circulation that carries warm tropical water northwards seem to be largely unfounded. New data - recorded between the Bahamas and the Canary Islands - show that the seemingly dramatic reduction discovered two years ago in the strength of the Atlantic meridional overturning circulation (MOC) is easily within the range of huge seasonal variability.

In 2005, a team led by Harry Bryden, an oceanographer at the University of Southampton, UK, reported a $30 \%$ decrease in the MOC at $26.5^{\circ}$ north, after comparing their measurements from ship-based instruments in 2004 with similar data from 1957, 1981, 1992 and 1998 (H. L. Bryden, H. R. Longworth and S. A. Cunningham Nature 438, 655-657; 2005). They did caution at the time that, due to the scarcity of observations, the error bounds of their study were exceptionally wide.

Nevertheless, the finding fuelled fears of an imminent collapse of the thermohaline Atlantic circulation - the ocean conveyor driven by temperature and salinity differences that gives rise to the Gulf Stream, allowing western Europe to enjoy a relatively mild climate. Alarmist headlines warned that a mini ice age would hit Britain.

However, 12 months' worth of data from an array of moored instruments, deployed during the same 2004 cruise that yielded the most recent measurements included in Bryden's study, now suggest that the observed changes were due to shortterm variability and not the result of global warming.

Stuart Cunningham of the National Oceanography Centre in Southampton and his colleagues found that the

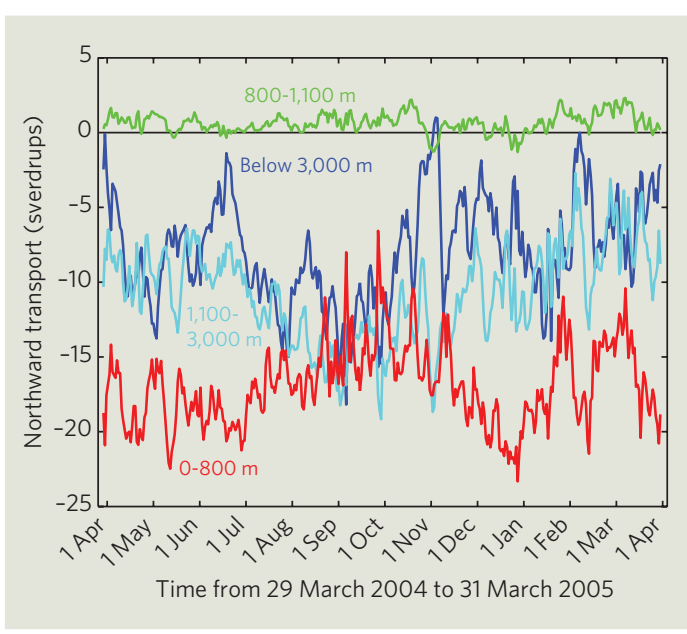

During just one year, Stuart Cunningham's team found enormous variability in the northwards flow of thermocline layer circulation (red), the deep waters of the upper (light blue), and the lower (dark blue) North Atlantic. Even the flow of intermediate water (green) fluctuated. 


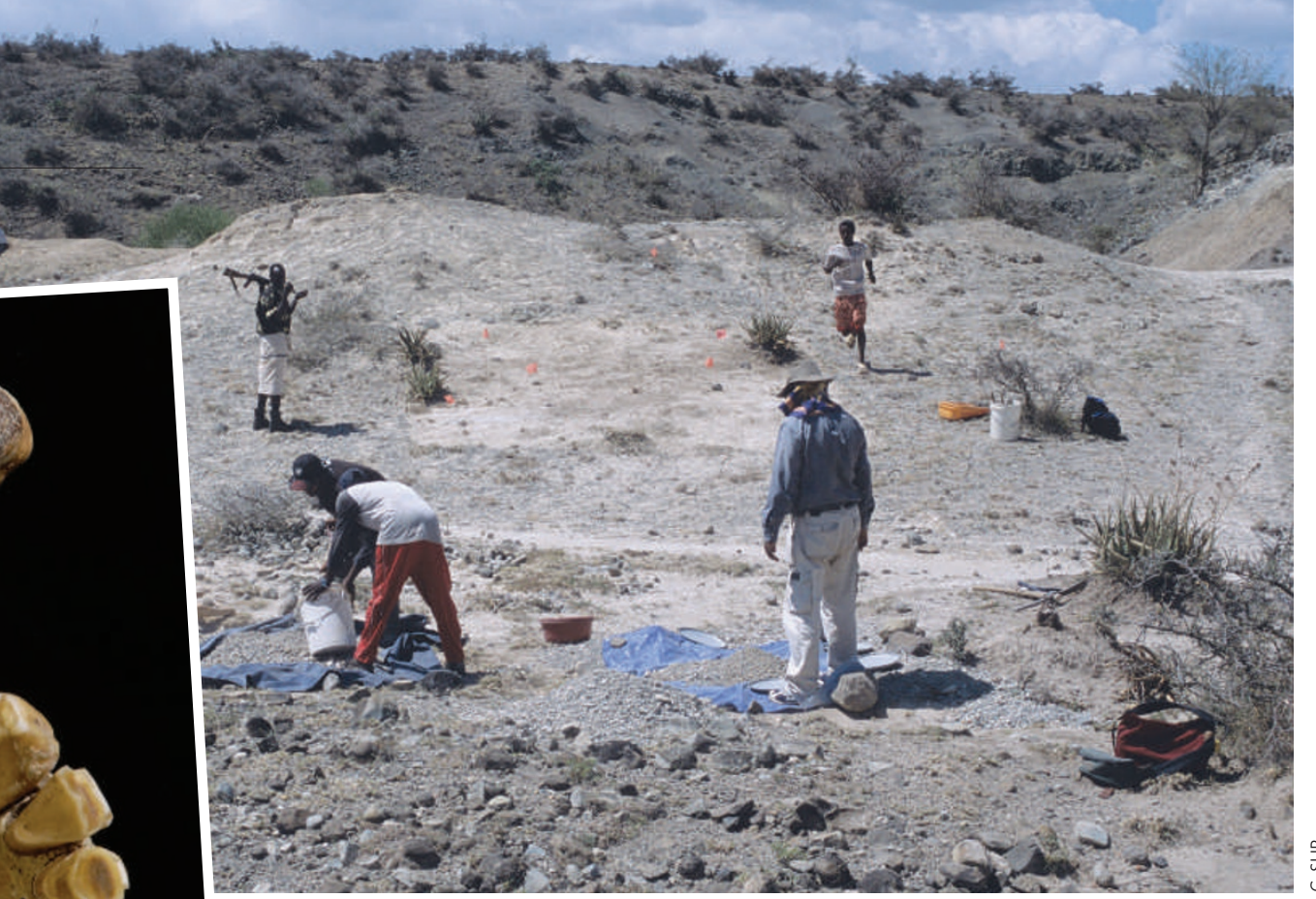

Fossilized teeth from the earliest-found gorilla (top, left), discovered at a site in Ethiopia (above), are remarkably similar to those of a modern gorilla (bottom, left).

and Asia for species that predate the earliest known hominid, the 7-million-yearold Sahelanthropus tchadensis (M. Brunet et al. Nature 418, 145-151; 2002)

Between 15 million and 22 million years ago, there were dozens of primate species across Africa and Euroasia - and apes dominated the primate scene. But fossils show that these species don't share the characteristics of modern African apes. "From that species pool, the common ancestor of African apes and humans branched out," says Tim White, a palaeoanthropologist at the University of California, Berkeley, and an RHOI director. "And the goal of RHOI is to find the common ancestors. With C. abyssinicus, we now can see an ancestral African ape."

Rex Dalton strength of the overturning circulation varied wildly - by a factor of 8 - between March 2004 and March 2005 (S. A. Cunningham et al. Science 317, 935-937; 2007). Bryden, who was also involved in the new study, had unknowingly probed the ocean during a period of relatively low circulation, they conclude.

"I guess we can give [thermohaline] the all-clear," says Jochem Marotzke, an oceanographer at the Max Planck Institute for Meteorology in Hamburg, Germany, formerly principal investigator of Rapid Climate Change (RAPID), a monitoring programme funded by the UK Natural Environment Research Council. The Atlantic sensor array, which is to remain operational until 2014, is part of the RAPID programme.
Available data provide no statistically significant evidence for a change of the overturning circulation over the past 50 years, says Marotzke, a co-author on the new study.

From now, the RAPID

system should allow researchers to detect circulation changes from one year to the next, provided the average circulation volume changes by $20 \%$ or more. But because the unknown variability from year to year may also be large, it will take at least ten more years of continuous measurements until a possible downward trend will become recognizable in the data noise.

But Bryden remains unconvinced that the RAPID measurements in the new study have rendered his initial findings null and void. The depth of the thermocline - the layer of rapid heat transfer between the mixedwater layer at the surface and deep-ocean water - varies across the basin from west to mid-ocean, changing the recirculation of water. An increase in the slope of the thermocline along with the observed freshening of deep water near the Bahamas, do indicate a 10-15\% decline in average circulation since 1980, Bryden maintains.

"RAPID is quite an achievement," Bryden says. "But I don't share the opinion that our previous results are just due to seasonal variability. It may not be statistically reliable, but all the science points to a slow down of the Atlantic circulation." Quirin Schiermeier
ON THE RECORD

C In our courses you will have the possibility to renew the natural contact you have with the angels. Use angels and your own power to create miracles in your own life.》”

Norway's Princess Märtha Louise's school for communicating with angels opens on 22 August and courses are already sold out. But TV pastor Jan Hanvold has unkindly called the clairvoyant princess "an emissary from hell". Sidelines wonders who the angels prefer to talk to.

\section{SCORECARD}

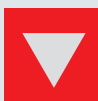
Left-clawed crabs You'd think that being a left-clawed Australian

fiddler crab when $98 \%$ are right-clawed would give you an advantage in a fight. But it turns out that left-clawed crabs are less likely to fight, and when they do, they usually lose. Perhaps that's why they are so much rarer...

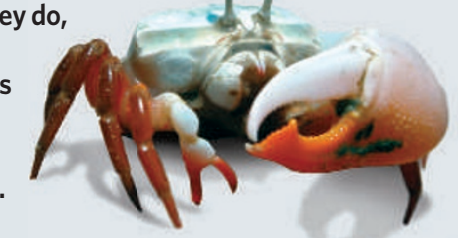

\section{Ghost crabs}

In a study involving offroad vehicles on sandy

Australian beaches scientists discovered that no ghost crabs buried less than $5 \mathrm{~cm}$ deep survive being run over 10 times, while more than $70 \%$ survive if buried at depths of $20 \mathrm{~cm}$. Someone should tell the crabs.

\section{NUMBER CRUNCH}

26 is the latest estimate of the maximum number of moves needed to solve any Rubik's cube.

63 hours is the time a supercomputer took to whittle down to this number from a best estimate of 29 moves.

\section{0-something is the}

theoretical estimate of the maximum number of moves ever needed - a number still unproven.

$\mathbf{4 3}$ billion billion is the total number of Rubik's cube positions.

Sources: BBC, Spiegel, Proc. R. Soc. B, Mar. Ecol.

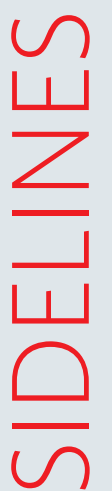

